Int. J. Dev. Biol. 56: 489-497 (2012)

doi: $10.1387 / \mathrm{ijdb} .113476 \mathrm{~cd}$

\title{
Interstitial stem cells in Hydra: multipotency and decision-making
}

\author{
CHARLES N. DAVID* \\ Department Biologie II, Ludwig-Maximilians-University Munich, Planegg-Martinsried, Germany
}

\begin{abstract}
Interstitial stem cells in Hydra constitute a population of multipotent cells, which continuously give rise to differentiated products during the growth and budding of Hydra polyps. They also give rise to germ cells in animals undergoing sexual differentiation. Cloning experiments have shown that interstitial stem cells are multipotent. In vivo tracing of stem cell lineages has revealed that stem cells divide symmetrically to yield two stem cells or asymmetrically to yield one stem cell daughter and one daughter cell which initiates nerve or nematocyte differentiation. Following commitment, some nerve cell precursors migrate from the body column into the head or foot region, thus giving rise to the high density of nerve cells observed in these regions. Stem cell proliferation is regulated by changes in the self-renewal probability and is controlled by stem cell density. Nerve cell commitment is controlled by several peptides including the Head Activator. Factors affecting nematocyte commitment are not known, but wnt and notch signaling are both required for differentiation of committed precursors.
\end{abstract}

KEY WORDS: Hydra, interstitial cell, stem cell, multipotency, germline, nerve cell, nematocyte

\section{Introduction}

Interstitial stem cells in Hydra constitute a population of multipotent cells, which continuously give rise to differentiated products during growth and budding of Hydra polyps. Interstitial cells were recognized in hydrozoans more than 100 years ago and early on shown to give rise to gametes when animals undergo sexual reproduction. Based on these observations Weissmann (1883) formulated his hypothesis on the continuity of the germline (for review see (Tardent, 1985)).

The interstitial stem cell system in Hydra has been the object of intense research over the past 40 years. A great deal is known about the cell kinetics of the system and the differentiation pathways. A number of cell-type-specific genes have been isolated and provide useful markers for cell differentiation. Most recently, the successful creation of transgenic Hydra expressing GFP in the interstitial cell lineage has greatly facilitated progress (Wittlieb et al., 2006). Several excellent reviews cover different aspects of the interstitial cell system (David et al., 1987, Bode, 1996, Bosch, 2009, Watanabe et al., 2009, Bosch et al., 2010). The present review will provide an introduction to basic features of the system and how these were discovered. The goal will be to show the advantages that the interstitial cell system has for understanding basic events of stem cell behavior.
Analysis of interstitial cell proliferation and differentiation was greatly facilitated by the introduction of the tissue maceration technique (Bode et al., 1973, David, 1973). Using this method, Hydra tissue can be easily and quantitatively dissociated to individual cells, which retain their in vivo morphology and hence are recognizable as distinct cell types. Cells from whole animals or tissue fragments can be accurately counted and hence quantitative data about the size of cell populations can be obtained. Macerated cells can be used for autoradiography, which permits labeling studies on the proliferation and turnover of cell populations in vivo. Immunostaining of macerated cells can be used to identify cell-type-specific antigens and to further analyse differentiation pathways.

\section{The interstitial cell system}

Fig. 1 shows phase contrast images of interstitial stem cells and several differentiated cell types in macerated tissue. Stem cells are large, undifferentiated cells with a conspicuous nucleus and nucleolus. They occur primarily as single cells or pairs of cells (referred to as $1 \mathrm{~s}+2 \mathrm{~s}$ ) held together by an intercellular bridge as a result of incomplete cytokinesis. Stem cells divide to yield further

Abbreviations used in this paper: HU, hydroxyurea; Ps, self-renewal probability.

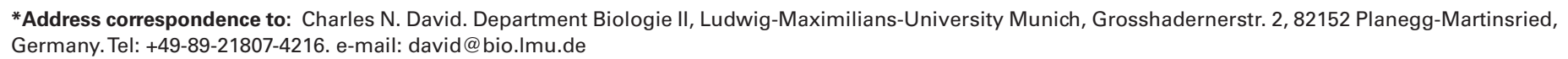


stem cells as well as precursors for the differentiation of nerve cells, gland and mucous cells, and nematocytes. The nematocyte pathway includes a series of synchronous cell divisions giving rise to nests of 4,8 and 16 cells followed by differentiation of a single nematocyst capsule in each cell of a nest ((Campbell and David, 1974, David and Gierer, 1974) see in this issue (Beckmann and Ozbek, 2012)). All cells in a nest differentiate the same nematocyst type; different nematocyst types are formed by different nests (Lehn, 1951, David and Challoner, 1974).

Interstitial stem cells also give rise to sperm and eggs in animals undergoing sexual reproduction. In both sexes, large nests of proliferating interstitial cells form by mitotic division. In males these nests undergo a terminal cell cycle followed by meiosis and the differentiation of sperm cells (Littlefield, 1985, Munck and David, 1985). During oogenesis, the large nests of mitotic cells complete a premeiotic S-phase and one to several of these premeiotic cells initiate oogenesis. The remaining cells differentiate as nurse cells before fusing with and transferring their cytoplasm to the developing oocytes. After cytoplasm transfer, the nurse cell ghosts undergo apoptosis and are phagocytosed by the oocyte (Alexandrova et al., 2005).

In asexually growing tissue, interstitial stem cells divide regularly with a cell cycle of about $24-30$ hours. About $60 \%$ of daughter cells remain stem cells, while the remaining $40 \%$ undergo differentiation to nerve cells, nematocytes or gland cells (David and Gierer, 1974). Under these conditions the stem cell population doubles in about 3-4 days at the same rate as the epithelial tissue. Thus parent animals and buds always contain similar proportions of epithelial cells, stem cells and differentiated products. Nerve cell

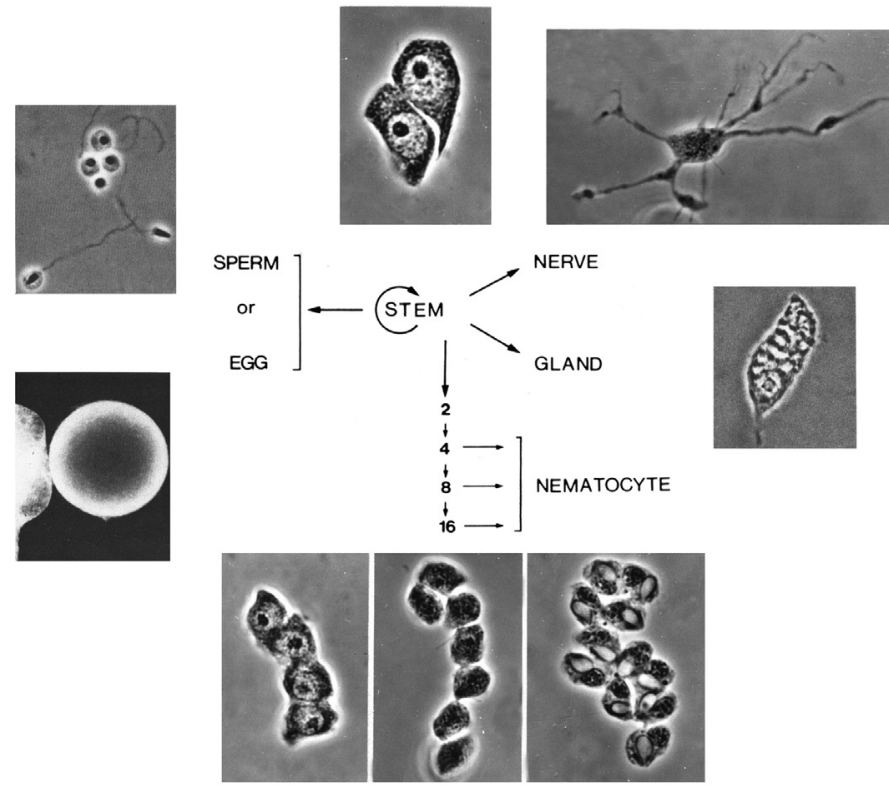

differentiation consumes about $10 \%$ of stem cells and nematocyte differentation about $30 \%$ of the stem cell population per generation. The number of gland and mucous cells differentiating per generation is not precisely known, because both cell populations also grow by mitotic divisions (Schmidt and David, 1986).

\section{Multipotency of interstitial stem cells}

The results above describe the behavior of the stem cell population as a whole and are consistent with the idea that interstitial stem cells are multipotent. Alternatively, there could be distinct populations of morphologically identical but committed stem cells each capable of giving rise to only one differentiated cell type. To resolve this issue, David and Murphy (1977) developed a method

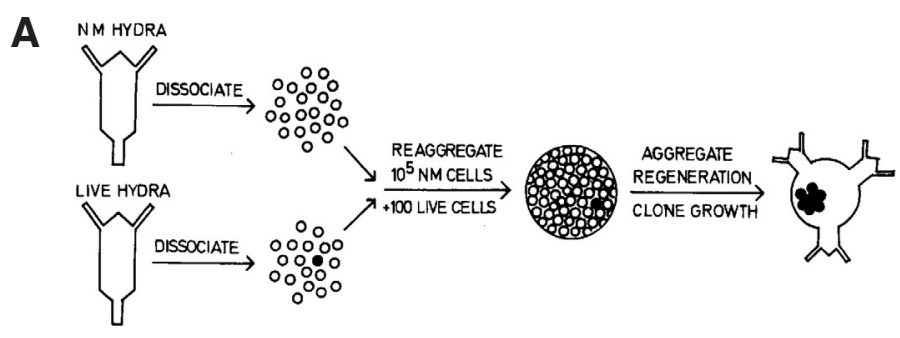

B

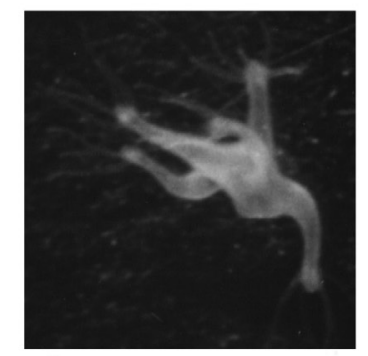

C

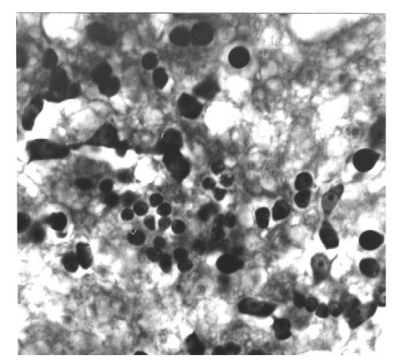

D

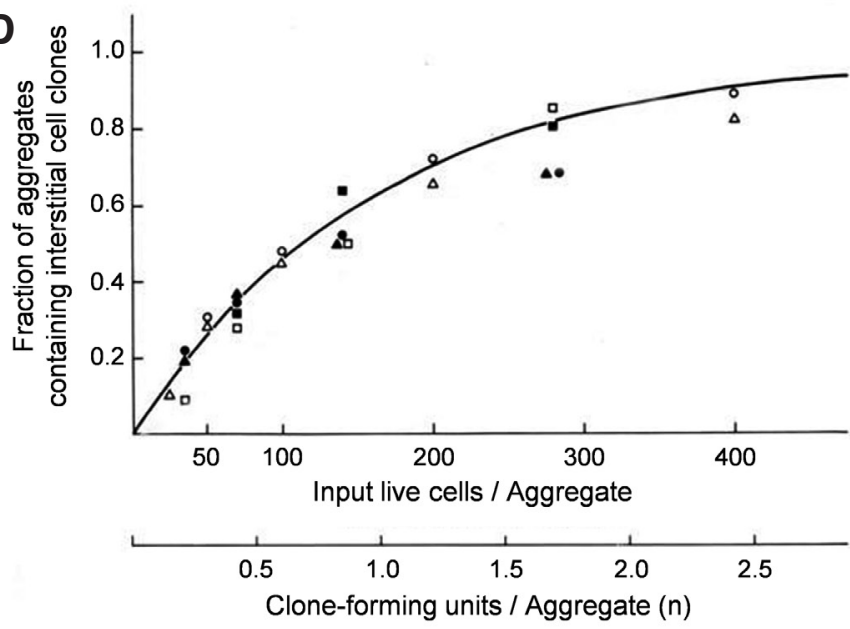

Fig. 1 (Left). The interstitial stem cell system in Hydra. Phase contrast images show the individual cell types in macerated tissue. The schematic in the center summarizes the proliferation and differentiation pathways. Modified from David (1973) and David et al., 1987).

Fig. 2 (Right). Cloning interstitial stem cells. (A) Schematic of the procedure for cloning stem cells in aggregates of nitrogen mustard (NM)-treated host tissue. (B) Typical aggregate after 7 days. (C) Stem cell clone containing about 150 cells after 10 days stained with toluidine blue. (D) Increase in stem cell clones with increasing input of live cells per aggregate. The curve follows Poisson single hit kinetics indicating that clones are founded by single cells. All clones contained both differentiated nerve cells and differentiated nematocytes, indicating that interstitial stem cells are multipotent. Different symbols indicate independent cloning experiments. Modified from David and Murphy (1977). 


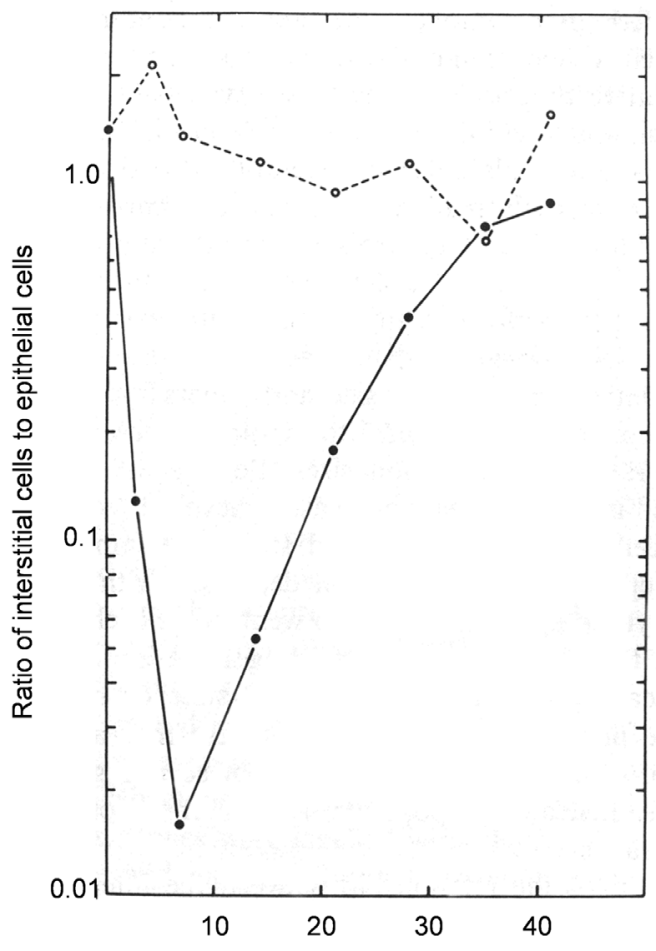

Time after start of hydroxyurea treatment (days)

Fig. 3. Recovery of the interstitial stem cell population following depletion by treatment with hydroxyurea (HU). Cell numbers are expressed as the ratio of interstitial cells to epithelial cells. Solid line: HU treated animals; dotted line: untreated control animals. Data from Bode, Flick and Smith (1976).

to clone stem cells in which small numbers of live cells were reaggregated with nitrogen mustard (NM) treated cells that served as a "feeder layer" and were not capable of further proliferation (Fig. 2A). This method is similar to the classic procedure for cloning hematopoetic stem cells in lethally irradiated mice (Till and McCulloch, 1961). Individual stem cell clones grew in the aggregates and could be visualized with toluidine blue staining (Fig. 2 B,C). Addition of increasing numbers of live cells gave rise to increasing numbers of clones. The increase followed single hit Poisson statistics indicating that clones arose from single cells (Fig. 2D).

To score cell differentiation in stem cell clones, aggregates containing low numbers of input cells, and hence single clones, were labeled with $3 \mathrm{H}$-thymidine and incubated for two days to permit differentiation of labeled nerve cells and nematocytes. All clones contained both labeled nematocyte nests and labeled nerve cells consistent with the hypothesis that stems cells are multipotent (David and Murphy, 1977).

The NM aggregates do not live long enough to score gamete

Fig. 4. Stem cell proliferation is regulated by changes in the self-renewal probability $\mathbf{P}_{\mathbf{s}}$. (A) Growth rate of interstitial cells $(1 \mathrm{~s}+2 \mathrm{~s})$ added at different densities to NM host aggregates (30 and 400 clone forming units per aggregate). Different symbols represent independent experiments. (B) Self-renewal probability $P_{s}$ decreases with increasing stem cell density in NM host aggregates. Different symbols represent independent experiments. Data from Sproull and David (1979a). Two large circled symbols represent $P_{s}$ calculated from single clones in NM aggregates. Data from David and MacWilliams (1978). differentiation. To achieve this result, an alternative cloning procedure was developed by Bosch and David $(1986,1987)$ using as host tissue the mutant strain sf-1 (Sugiyama and Fujisawa, 1977), which has temperature sensitive stem cells that can be eliminated from tissue by incubation at $28^{\circ} \mathrm{C}$. The epithelial tissue is not damaged by this treatment and sf- 1 aggregates develop into normal animals, which can grow and bud normally if provided with a source of interstitial stem cells. Using this procedure, 92 clones were obtained, of which 87 differentiated sperm or eggs over the course of 6 months. All the clones contained differentiated nematocytes and nerve cells. These results confirmed that interstitial stem cells in Hydra are multipotent and indicated furthermore that nearly all can differentiate both somatic cells and gametes. Nevertheless, stem cell lines differentiating only sperm or egg have been obtained by alternative procedures suggesting that such cells are present at a low frequency in normal animals (Littlefield, 1985, Littlefield, 1991, Nishimiya-Fujisawa and Sugiyama, 1993). They appear to be intermediates between multipotent stem cells and terminally differentiated sperm or egg (Littlefield, 1994). See in this issue (Nishimiya-Fujisawa and Kobayashi, 2012).

\section{Regulation of stem cell proliferation}

Hydra polyps grow asexually by budding and it appears that they can grow indefinitely (Brien, 1953, Martinez, 1998). Polyps taken from cultures at different times always have roughly the same proportion of interstitial stem cells and differentiated products relative to the epithelial cells. Since epithelial cells and interstitial stem cells represent independent lineages (Watanabe et al., 2009, Bosch et al., 2010), some form of feedback must control these cell
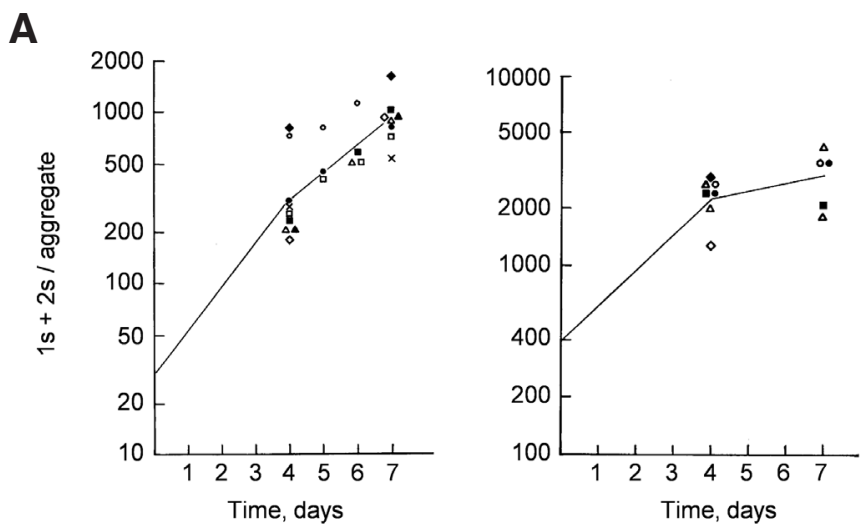

B

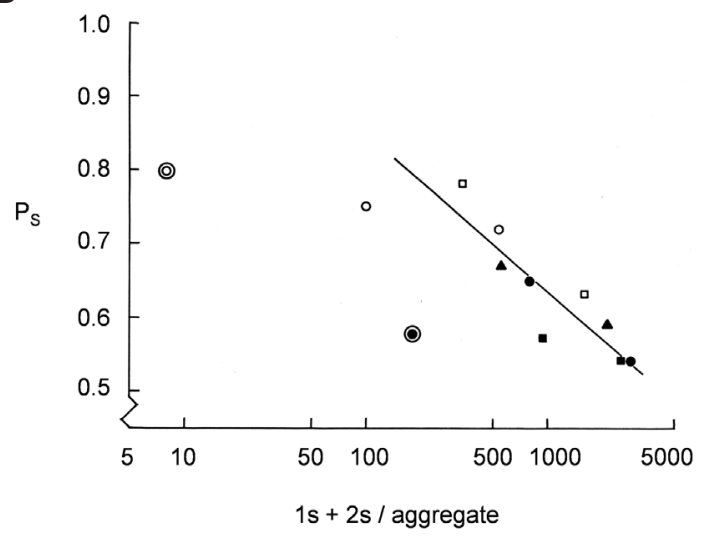


proportions. Bode et al., (1976) demonstrated this feedback signal directly by depleting the stem cell population with hydroxyurea treatment (HU blocks DNA replication in S-phase, activates a cell cycle checkpoint and the apoptosis of affected cells). All cells in a polyp are sensitive to HU treatment, but the short cell cycle of stem cells makes them particularly sensitive. Fig. 3 shows that $\mathrm{HU}$ treatment for 3 days reduced the level of interstitial cells to $1-2 \%$ of normal but that over a period of 3 weeks following $\mathrm{HU}$ treatment, stem cell levels recovered completely. Since the stem cell cycle did not change significantly in these experiments, the authors concluded that a higher fraction of daughter cells remained stem cells per cell division.

To test this conclusion directly, Sproull and David (1979a, $1979 b$ ) varied the density of stem cells experimentally by adding different numbers of stem cells to NM aggregates. The results in Fig. 4A demonstrate clearly that the growth rate of the interstitial cell population in aggregates was higher at low density (doubling time: $\mathrm{Td}$ about 2 days) and lower at high density ( $\mathrm{Td}>5$ days). In these experiments, the cell cycle of the stem cells did not change at different stem cell densities. The results clearly demonstrate that the fraction of daughter cells remaining stem cells - the selfrenewal probability $\left(P_{s}\right)$ - increased at lower stem cell densities and hence increased the growth rate of the stem cell population. Fig. 4B summarizes results from a variety of experiments confirming this conclusion. It also shows estimates of $P_{s}$ from single clones (David and MacWilliams, 1978), which demonstrate the same decrease in

A

stem cell lineages showing differentiation

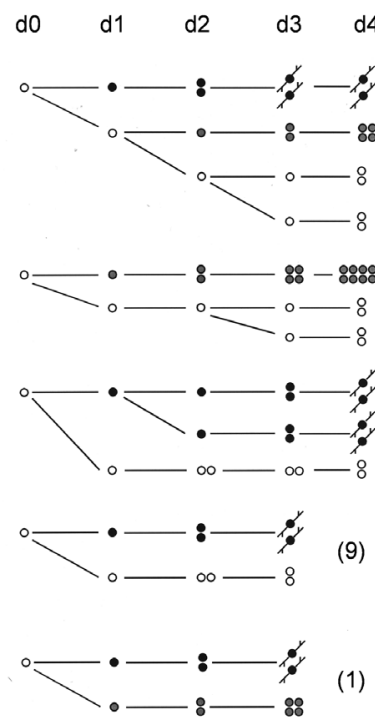

B stem cell lineages showing self-renewal
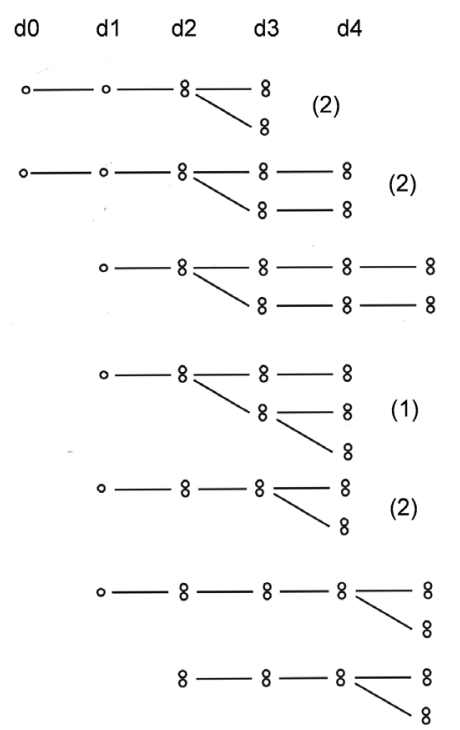

$8-8-8-8$
$P$ with increasing stem cell density (within the clone). This leads to the conclusion that the density feedback mechanism (signal) has a short range. In other words, stem cells can estimate the number of neighboring stem cells, but are insensitive to the presence of stem cells at greater distances. The nature of the feedback signal is presently unknown.

\section{Stem cell decision-making: commitment to nerve and Nematocyte differentiation}

Commitment is usually defined as the ability of cells to continue differentiation in the absence of stimulating signals. It can be tested by assaying the differentiation ability of cells removed from tissue and placed, for example, in cell culture. In Hydra this can be achieved by dissociating tissue to single cells and transferring the cells to re-aggregates as shown in the cloning experiments (Fig. 2) or simply by isolating small tissue fragments. These fragments rapidly seal up to form hollow balls of tissue, which over the course of 4-5 days will regenerate. Using such assays, nerve cell commitment was shown to occur in the S-phase of a precursor cell (Venugopal and David, 1981a, Venugopal and David, 1981b). Committed cells completed the cell cycle, divided, and daughter cells differentiated to nerve cells. Hager and David (1997) confirmed these results by labeling interstitial cells in vivo with the fluorescent dye Dil and tracing the differentiation of nerve precursors. These experiments showed that commitment in early S-phase was frequently accompanied by migration of precursors from the body column toward head or peduncle regions before the terminal mitosis and differentiation of the two daughters as nerve cells (see Fig. 6A).

A similar experiment demonstrated that cells in nests of nematocyte precursors were committed to complete a program of cell divisions and to differentiate nematocyst capsules (Fujisawa and David, 1981). When nests were separated into individual cells by the dissociation procedure, the individual cells were capable of continuing proliferation and differentiation in NM aggregates. This gave rise to a temporal series of unusually small nests, first singles, then twos, fours and eights, before the typical distribution of nest sizes was restored by renewed proliferation from stem cells.

\section{Stem cell lineages}

The cloning and growth experiments described above make it clear that individual stem cells in Hydra make decisions, first between stem cell and differentiated cell and second as to which type of differentiated cell. At present little is known about how such decisions are made and what signals affect the decisions. While for many years it appeared that position along the body column influenced the decision for nerve cell or nematocyte differentiation (David and Challoner, 1974, David and Gierer, 1974, David and Plotnick, 1980, Venugopal and David, 1981c), the evidence for this has become less convincing since it became clear that nerve precursors migrate from the gastric region into the head and foot before differentiating (Heimfeld and Bode, 1984, Teragawa
Fig. 5. Stem cell lineages traced by labeling cells in vivo with Dil. (A) Lineages in which stem cells (open circle) divided asymmetrically to yield a nerve cell precursor (black circle) or a nematocyte precursor (grey circle) and one stem cell daughter. One lineage yielded two differentiated daughter cells. (B) Lineages in which single stem cells divided to yield a pair of stem cells (self-renewal); stem cell pairs also divided to yield two pairs of stem cells (self-renewal). Lineages were examined once each day. All lineages start on day 0 but are aligned to the first division where a single cell divided to yield two daughter cells. The number of examples of each lineage is shown in parentheses. A schematic of the site of Dil injection is shown in Fig. 6A. Data from Hager (1997). 
and Bode, 1995, Technau and Holstein, 1996, Hager and David, 1997). Thus, a significant cause of the asymmetric distribution of nerve cells along the body column is cell migration (see below). In particular, it is now clear that the increased nerve cell differentiation associated with head regeneration is a consequence of precursor migration into the site of regeneration (Fujisawa, 1989).

To learn more about the decision-making process, Hager and David (1997) developed a method to stain small patches of interstitial cells in vivo with the fluorescent carbocyanin dye Dil (Fig. 5 and 6 ) and then to track the growth and differentiation of individual stem cell lineages on a daily basis. From the morphology of the stained cells it was possible to identify cell types. Nerve cells are easily recognized due to their long thin processes. Nematocyte differentiation is characterized by formation of a nest of precursor cells. By the 4-cell stage such nests are clearly recognizable as nematocyte precursors although nematocyst differentiation requires at least another 3-4 days to complete. Stem cells occur as undifferentiated cells, either as single cells or in pairs. Although such cells are not directly distinguishable from early precursors in the nerve and nematocyte pathways, the absence of further changes suggest that such cells are indeed stem cells.

Based on these criteria it was possible to analyse about 50 individual stem cell lineages (Fig. 5) (Hager, 1997). While the data are limited, they do document three different types of stem cell decisions directly:

A

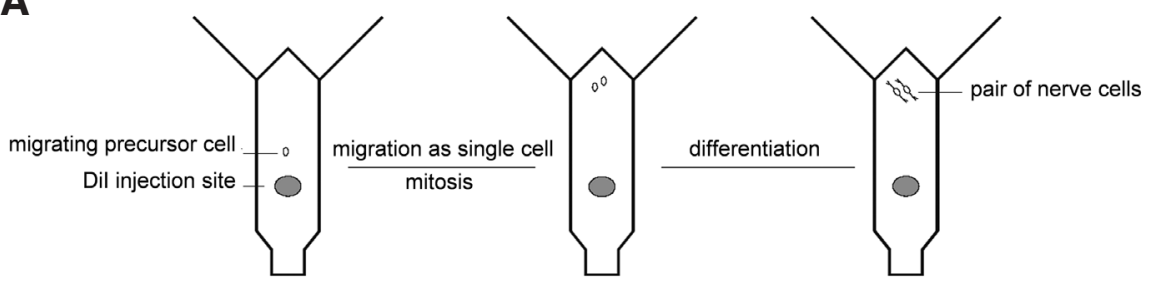
day 1
1. stem cells divide to yield one differentiated cell and one stem cell

2. stem cells divide to yield two different daughter cells: one nerve cell precursor and one nematocyte precursor

3. stem cells divide to yield two stem cells

All cases of nerve and nematocyte differentiation started from an asymmetric cell division in which a single interstitial cell gave rise to one daughter cell, which initiated a stereotypic nerve or nematocyte differentiation pathway, and one daughter cell, which appeared to be a stem cell (Fig. 5A). There was one case in which a single stem cell gave rise to one nerve and one nematocyte precursor, thus extinquishing the stem cell lineage. Thus, in all cases the differentiation pathway started from a single daughter cell following an asymmetric division.

Three lineages demonstrated multipotency directly, i.e. gave rise to different types of differentiated cells in successive divisions. While this number is small, it appears likely that this is due to the limited time over which Dil labeled clones could be tracked in vivo.

Interstitial cells, which showed no sign of differentiation over the course of the experiment, were assumed to be stem cells. Fig. 5B shows 30 examples of such lineages. Interestingly, stem cell proliferation appears to occur by division of single interstitial cells to yield a pair of interstitial cells or by division of a pair to yield two pairs of interstitial cells. There were no cases of single interstitial cells giving rise to two single interstitial cells. In all the cases where this happened, one of the daughter cells always differentiated (see Fig. 5A). One implication from these observations is that pairs of interstitial cells must separate into two single interstitial cells prior to an asymmetric division which gives rise to a differentiated cell.

\section{Nerve cell differentiation: precursor mi- gration and the spatial pattern of nerve cells in Hydra}

Astriking feature of the interstitial cell system is that, in many cases, differentiated products migrate away from the site of formation to a final site of function. In the case of nematocytes this has been clear for a long time. Nematocyte differentiation occurs in nests in the gastric region, while mature nematocytes are located primarily in the tentacles. In the case of nerve cells, the issue has been less clear. Mature nerve cells are located throughout the body column, although there is an increased density of nerve cells in the head and tentacles and in the basal disk. Where the precursors for these nerve cells were located was initially not clear.

A series of grafting experiments with labeled precursors showed extensive migration of nerve precursors from the body column to head and peduncle tissue (Heimfeld and Bode, 1984, Teragawa and Bode, 1995). These results were confounded, however, by experiments showing that cutting stimulated nerve precursor migration (Fujisawa et al., 1990). Resolution of this problem came with the help of a method for labeling cells in situ with the fluorescent dye Dil and following the differentiation of nerve
Fig. 6. Nerve cell differentiation traced in vivo by Dil labeling of precursors. (A) Schematic of Dil injection site and Dillabeled precursor migrating out of a labeled patch toward the head. During migration the precursor cell completes the cell cycle, divides and gives rise to two nerve cells in the head. Only nerve precursors were observed to migrate out of Dil-labeled patches. (B) Number of nerve precursors differentiating locally (in situ) or migrating out of Dil-labeled patches in head, body column and peduncle over 4 day interval. Modified from Hager and David (1997). 
cells in living animals in the absence of experimental manipulation (Hager and David, 1997). The results were quite surprising. Some Dil-labeled interstitial cells differentiated directly, without migrating, to nerve cells in Dil labeled patches in the middle of the gastric region, while other labeled cells migrated out of the patches toward the head and foot regions before differentiating to nerve cells (Fig. 6A). These cells always migrated as single interstitial cells. When they reached a destination in the head, for example, they stopped migration, divided to yield two daughter cells and each of the daughter cells then differentiated into a nerve cell and integrated into the existing nerve net.

The behavior of nerve precursors in Dil-labeled patches in the head and in the foot was quite different. In these cases, nearly all the Dil-labeled precursors, completed the cell cycle without migrating and differentiated as a pair of labeled nerve cells in situ. Quantitative analysis showed that about half of all nerve precursors in the body column migrated toward the head or foot region (Fig. 6B). By comparison essentially no nerve precursors in head and foot tissue migrated out of labeled patches. Furthermore, the number of labeled nerve cells differentiating from a labeled patch was roughly the same in all three regions of the body column. Thus the pattern of nerve cells along the body column appears to be due

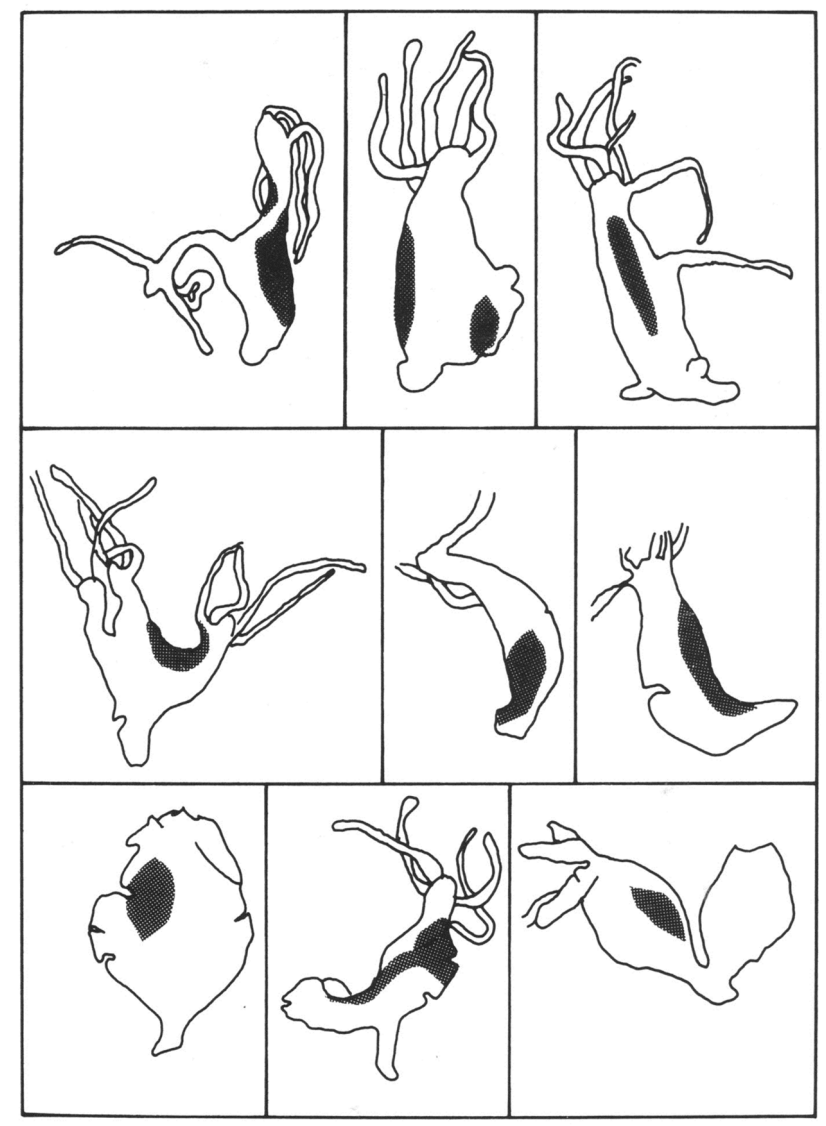

Fig. 7. Stem cell clones grow as contiguous patches in vivo. Wildtype strain 105 cells were cloned in aggregates of strain sf-1 (temperaturesensitive interstitial cells). After two weeks of clone growth, the aggregates were heat shocked to eliminate host sf-1 cells and the wildtype strain 105 cells were detected by toluidine blue staining. The dark patches indicated the location of single strain 105 stem cell clones. Data from Bosch and David (1991). to migration of nerve precursors and not to a difference in the rate of nerve cell commitment in the three regions of the body column.

The only migrating cells observed in Dil labeling experiments were those which differentiated to nerve cells. Nests of differentiating nematocytes did not migrate out of labeled patches (although mature single nematocytes do migrate). Stem cells also did not migrate out of patches. Both results are in agreement with previous experiments showing that stem cells grow as contiguous patches in undisturbed animals (Fig. 7) (Bosch and David, 1990).

\section{Regulation of stem cell decisions - stochastic or not?}

How stem cells make decisions for self-renewal or differentiation is not well understood in any stem cell system (Lander, 2009, Lander, 2011). The two extreme models are: (1) asymmetric division, in which individual stem cells always divide to yield one stem cell and one differentiated cell. There is no room in such a model for regulation of stem cell numbers or growth of the stem cell population without additional assumptions. (2) stochastic behavior, in which stem cells decide at some frequency for specific fates, i.e. to remain stem cells or to differentiate. This will yield a variety of fates but is not able to regulate, without assuming that the stochastic probabilities can be modified by environmental cues, e.g. signaling molecules.

Regulation of stem cell populations following experimental perturbation is a remarkable feature of many stem cell systems, including the stem cell system in Hydra. The ability to regulate strongly suggests that stem cell decision-making cannot occur exclusively by asymmetric divisions or by stochastic differentiation probabilities. Rather, the occurrence of regulation demonstrates that stem cell behavior responds to signals from the environment. There is good evidence for such signals in Hydra, several of which are discussed below. The signals affect both the self-renewal probability and the type of differentiation. While the molecular nature of some signals is known, their mode of action is generally unknown; for other signals the molecular nature is not known. There is still a lot to learn (see in this issue the review by (Hobmayer et al., 2012).

\section{Factors regulating stem cell proliferation exist, but we don't yet know their identities}

The ability of the Hydra stem cell system to recover from experimentally reduced levels indicates that stem cells can sense their numbers in tissue. The results of Bode et al., (1976) and Sproull and David (1979a) clearly showed that this signal regulates $P_{s}$, the fraction of daughter cells remaining stem cells per cell generation. At lower stem cell densities, more stem cell daughters remain stem cells and thus increase the size of the stem cell population. The nature of the feedback signal is unknown, but it appears to be of short range, since stem cells in young clones having few cells already initiate differentiation.

Asecond factor, apparently derived from nerve cells, also strongly affects stem cell proliferation (Heimfeld and Bode, 1985, Bosch et al., 1991). When stem cells are introduced at low density into nerve free tissue, they grow very slowly contrary to the expectation based on their low density. The same cells introduced into tissue containing nerve cells grow rapidly and demonstrate the response to low stem cell density described above. The nature of the nerve cell factor is presently unknown, but it has a long range in tissue, 
since nerve cells in the proximal body column can support rapid stem cell proliferation in the distal body column.

A final enigmatic result demonstrates that the density effect on stem cell proliferation is strain specific (David et al., 1991). Strain 105 stem cells introduced at low density into sf- 1 tissue grew rapidly and hence were unable to sense the presence of host stem cells. Other strain combinations showed similar results.

\section{Factors regulating nerve cell differentiation}

Several such factors have been identified, but a clear picture has not yet emerged. Schaller (1973, Schaller and Bodenmuller, 1981 ) isolated a peptide that stimulated head regeneration, the Head Activator, from Hydra and Holstein et al., (Holstein and David, 1986, Holstein et al., 1986) showed that Hydra extracts containing this factor stimulated commitment of stem cells to nerve cell differentiation. A second "cutting" signal was also required to achieve differentiation of the committed precursors. These authors also showed that synthetic Head Activator peptide (pEPPGGSKVILF), at the concentration found in tissue extracts $(0.1 \mathrm{pM})$, stimulated nerve cell commitment and that commitment occurred in S-phase. While these experiments appear quite convincing, the Hydra genome sequence has not revealed a Head Activator gene ((Chapman et al., 2010); see also in this issue (Steele, 2012)) and hence the origin of the active peptide remains elusive.

A second peptide, Hym355, was identified in the Hydra Peptide Project (Takahashi et al., 1997) and also shown to stimulate nerve cell differentiation. Treatment of Hydra with Hym355 (FPQSFL$\mathrm{PRGa}$ ) induces nerve cell differentiation with similar kinetics to Head Activator suggesting that stem cell decisions are involved. Hym355 is a neuropeptide, localized in nerve cells in head and tentacles and in the basal disk, but also in scattered nerve cells in the body column. Hym355 appears to be involved in a positive feedback loop stabilizing the pattern of nerve cells throughout Hydra tissue. A second peptide, Hym33H (AALPW), which is synthesized by epithelial cells, counteracts the effect of Hym355 (Takahashi et al., 2000).

\section{Factors regulating nematocyte differentiation}

The wnt pathway has been identified in Hydra (Hobmayer et al., 2000) and shown to be involved in formation of the head organizer and the oral-aboral axis. A number of wnt genes are expressed at a high level in the tip of the hypostome. Ectopic activation of wnt signaling by treatment with the GSK inhibitor alsterpaullone induces ectopic hypostome formation throughout the body column (Broun et al., 2005). Khalturin et al., (2007) have now shown that alsterpaullone treatment inhibits nematocyte differentiation. Alsterpaullone treatment for two days eliminated cells expressing the nematocyte specific gene nb035. Since the nb035 gene is only expressed in postmitotic nests of differentiating nematocytes, this result is consistent with the idea that alsterpaullone blocks postmitotic terminal differentiation. An effect of alsterpaullone earlier in the nematocyte pathway, e.g. at the onset of nest proliferation, would not have led to a block in nb035 expression until after 3-4 days.

Notch signaling has also been shown to play a role in nematocyte differentiation. Treatment of Hydra with DAPT, an inhibitor of the gamma secretase, blocks notch signaling (Kasbauer et al., 2007). DAPT treatment strongly inhibited differentiation of nemato- cyte precursors during the postmitotic phase in which nematocyst capsules are formed (Kasbauer et al., 2007, Khalturin et al., 2007). The results indicate that notch signaling is required for survival and differentiation of these postmitotic precursors. Formation of nests of proliferating precursors was not affected by DAPT treatment.

In contrast to wnt activation and notch inhibition, both of which affect differentiation of nematocyte nests, lithium treatment appears to affect the decision of stem cells to form a nest of proliferating nematocyte precursors (Hassel and Berking, 1988). In Hydra treated with $1 \mathrm{mM}$ lithium there was initially no change in the number of nests of differentiating nematocytes in the body column but then an abrupt and complete loss of late stage differentiating cells on day 6 (desmonemes) and day 7 (stenoteles). This agrees well with the fact that nematocyte formation involves first 2-3 days of proliferation to form a nest of 8 and 16 precursors cells and then 2-3 days for differentiation of nematocyst capsules. The result also suggests that lithium treatment may affect stem cell decision-making directly, in contrast to wnt activation and notch inhibition, which affect differentiation of postmitotic nematocyte nests. Because lithium is known to have multiple targets (GSK3 and G-protein receptors), it is not clear how the effect works.

\section{Summary and outlook}

The results summarized in this review show that the Hydra interstitial cell system has useful features for getting at central questions in stem cell biology. The availability of GFP-labeled stem cells coupled with new methods for live cell microscopy on intact animals will permit tracing of stem cell lineages in vivo in real time. Together with the ability to manipulate the environment in vivo and the evidence that this environment affects stem cell decisions, it seems clear that the hydra stem cell system is well positioned to answer basic questions about stem cell decision-making.

\section{References}

ALEXANDROVA, O., SCHADE, M., BOTTGER, A. and DAVID, C.N. (2005). Oogenesis in Hydra: nurse cells transfer cytoplasm directly to the growing oocyte. Dev. Biol. 281: 91-101.

BECKMANN, A., OZBEK, S. (2012). The Nematocyst: A molecular map of the cnidarian stinging organelle. Int J Dev Biol 56: 577-582.

BODE, H.R. (1996). The interstitial cell lineage of hydra: a stem cell system that arose early in evolution. J. Cell Sci. 109: 1155-1164.

BODE, H.R., BERKING, S., DAVID, C.N., GIERER, A., SCHALLER, C.H. and TRENKNER, E. (1973). Quantitative analysis of cell types during growth and morphogenesis in Hydra. Roux's Arch Dev. Biol. 171: 269-285.

BODE, H.R., FLICK, K.M. and SMITH, G.S. (1976). Regulation of interstitial cell differentiation in Hydra attenuata. I. Homeostatic control of interstitial cell population size. J. Cell Sci. 20: 29-46.

BOSCH, T.C. (2009). Hydra and the evolution of stem cells. BioEssays 31: 478-486. BOSCH, T.C., ANTON-ERXLEBEN, F., HEMMRICH, G. and KHALTURIN, K. (2010). The Hydra polyp: nothing but an active stem cell community. Dev. Growth Differ. 52: $15-25$.

BOSCH, T.C. and DAVID, C.N. (1986). Male and female stem cells and sex reversa in Hydra polyps. Proc. Natl. Acad. Sci. USA 83: 9478-9482.

BOSCH, T.C. and DAVID, C.N. (1987). Stem cells of hydra magnipapillata can differentiate into somatic and germ line cells. Dev. Biol. 121: 182-191.

BOSCH, T.C. and DAVID, C.N. (1990). Cloned interstitial stem cells grow as contiguous patches in hydra. Dev. Biol. 138: 513-515.

BOSCH, T.C., ROLLBUHLER, R., SCHEIDER, B. and DAVID, C.N. (1991). Role of the cellular environment in interstitial stem cell proliferation in hydra. Roux's Arch. 
Dev. Biol. 200: 269-276.

BRIEN, P. (1953). La Perennite Somatique. Biological Reviews 28: 308-349.

BROUN, M., GEE, L., REINHARDT, B. and BODE, H.R. (2005). Formation of the head organizer in hydra involves the canonical Wnt pathway. Development 132: 2907-2916.

CAMPBELL, R.D. and DAVID, C.N. (1974). Cell cycle kinetics and development of Hydra attenuata. II. Interstitial cells. J. Cell Sci. 16: 349-358.

CHAPMAN, J.A., KIRKNESS, E.F., SIMAKOV, O., HAMPSON, S.E., MITROS, T., WEINMAIER, T., RATTEI, T., BALASUBRAMANIAN, P.G., BORMAN, J., BUSAM D. et al., (2010). The dynamic genome of Hydra. Nature 464: 592-596.

DAVID, C.N. (1973). A quantitative method for maceration of hydra tissue. Roux's Arch. Dev. Biol. 171: 259-268.

DAVID, C.N., BOSCH, T.C.G., HOBMAYER, B., HOLSTEIN, T.W. and SCHMIDT, T. (1987). Interstitial stem cells in hydra. In Genetic regulation of development, (ed. LOOMIS, W. F.), pp. 189-408. New York: Alan R Liss.

DAVID, C.N. and CHALLONER, D. (1974). Distribution of interstitial cells and differentiating nematocytes in nests in Hydra attenuata. American Zool. 14: 537-542.

DAVID, C.N., FUJISAWA, T. and BOSCH, T.C. (1991). Interstitial stem cell proliferation in hydra: evidence for strain-specific regulatory signals. Dev. Biol. 148: 501-507.

DAVID, C.N. and GIERER, A. (1974). Cell cycle kinetics and development of Hydra attenuata. III. Nerve and nematocyte differentiation. J. Cell Sci.16: 359-375.

DAVID, C.N. and MACWILLIAMS, H. (1978). Regulation of the self-renewal probability in Hydra stem cell clones. Proc. Natl. Acad. Sci. USA 75: 886-890.

DAVID, C.N. and MURPHY, S. (1977). Characterization of interstitial stem cells in hydra by cloning. Dev. Biol. 58: 372-383.

DAVID, C.N. and PLOTNICK, I. (1980). Distribution of interstitial stem cells in Hydra. Dev. Biol. 76: 175-184.

FUJISAWA, T. (1989). Role of interstitial cell migration in generating position-dependent patterns of nerve cell differentiation in Hydra. Dev. Biol. 133: 77-82.

FUJISAWA, T. and DAVID, C.N. (1981). Commitment during nematocyte differentiation in Hydra. J. Cell Sci. 48: 207-222.

FUJISAWA, T., DAVID, C.N. and BOSCH, T.C. (1990). Transplantation stimulates interstitial cell migration in hydra. Dev. Biol. 138: 509-512.

HAGER, G. (1997). In vivo Untersuchungen zum Differenzierungsverhalten Interstitieller Zellen in Hydra vulgaris (Coelenterata). PhD Dissertation. Ludwig-MaximiliansUniversitat. Munchen. pp. 1-136.

HAGER, G. and DAVID, C.N. (1997). Pattern of differentiated nerve cells in hydra is determined by precursor migration. Development 124: 569-576.

HASSEL, M. and BERKING, S. (1988). Nerve cell and nematocyte production in hydra is deregulated by lithium ions. Roux's Arch. Dev. Biol. 197: 471-475.

HEIMFELD, S. and BODE, H.R. (1984). Interstitial cell migration in Hydra attenuata. II. Selective migration of nerve cell precursors as the basis for position-dependent nerve cell differentiation. Dev. Biol. 105: 10-17.

HEIMFELD, S. and BODE, H.R. (1985). Growth regulation of the interstitial cell population in hydra. I. Evidence for global control by nerve cells in the head. Dev. Biol. 110: 297-307.

HOBMAYER, B., JENEWEIN, M., EDER, D., GLASAUER, S., GUFLER, S., HARTL, M. and SALVENMOSER, W. (2012). Stemness in Hydra - a current perspective. Int J Dev Biol 56: 509-517.

HOBMAYER, B., RENTZSCH, F., KUHN, K., HAPPEL, C.M., VON LAUE, C.C., SNYDER, P., ROTHBACHER, U. and HOLSTEIN, T.W. (2000). WNT signalling molecules act in axis formation in the diploblastic metazoan Hydra. Nature 407: 186-189.

HOLSTEIN, T.W. and DAVID, C.N. (1986). The properties of nerve cell precursors in hydra. Dev. Biol. 115: 18-26.

HOLSTEIN, T.W., SCHALLER, C.H. and DAVID, C.N. (1986). Nerve cell differentiation in hydra requires two signals. Dev. Biol. 115: 9-17.

KASBAUER, T., TOWB, P., ALEXANDROVA, O., DAVID, C.N., DALL'ARMI, E., STAUDIGL, A., STIENING, B. and BOTTGER, A. (2007). The Notch signaling pathway in the cnidarian Hydra. Dev. Biol. 303: 376-390.

KHALTURIN, K., ANTON-ERXLEBEN, F., MILDE, S., PLOTZ, C., WITTLIEB, J., HEMMRICH, G. and BOSCH, T.C. (2007). Transgenic stem cells in Hydra revea an early evolutionary origin for key elements controlling self-renewal and differentiation. Dev. Biol. 309: 32-44
LANDER, A.D. (2009). The 'stem cell' concept: is it holding us back? J. Biol. 8: 70. LANDER, A.D. (2011). The individuality of stem cells. BMC biology 9: 40.

LEHN, H. (1951). Teilungsfolgen und Determination von I-Zellen fur die Cnidienbildung bei Hydra. Zeitschrift fur Naturforschung 66: 388-391.

LITTLEFIELD, C.L. (1985). Germ cells in Hydra oligactis males. I. Isolation of a subpopulation of interstitial cells that is developmentally restricted to sperm production. Dev. Biol. 112: 185-193.

LITTLEFIELD, C.L. (1991). Cell lineages in Hydra: isolation and characterization of an interstitial stem cell restricted to egg production in Hydra oligactis. Dev. Biol. 143: 378-388.

LITTLEFIELD, C.L. (1994). Cell-cell interactions and the control of sex determination in hydra. Sem. Cell and Dev. Biol. 5: 13-20.

MARTINEZ, D.E. (1998). Mortality patterns suggest lack of senescence in hydra Exp. Gerontol. 33: 217-225.

MUNCK, A. and DAVID, C.N. (1985). Cell proliferation and differentiation kinetics during spermatogenesis in Hydra carnea. Roux's Arch. Dev. Biol. 194: 247-256.

NISHIMAYA-FUJISAWA, C. (2012). Germline stem cells and sex determination in Hydra. Int J Dev Biol 56: 499-508.

NISHIMIYA-FUJISAWA, C. and SUGIYAMA, T. (1993). Genetic analysis of developmental mechanisms in hydra. XX. Cloning of interstitial stem cells restricted to the sperm differentiation pathway in Hydra magnipapillata. Dev. Biol. 157: 1-9.

SCHALLER, H.C. (1973). Isolation and characterization of a low-molecular-weight substance activating head and bud formation in hydra. J. Embryol. Exp. Morphol. 29: 27-38.

SCHALLER, H.C. and BODENMULLER, H. (1981). Isolation and amino acid sequence of a morphogenetic peptide from hydra. Proc. Natl. Acad. Sci. USA 78: 7000-7004.

SCHMIDT, T. and DAVID, C.N. (1986). Gland cells in Hydra: cell cycle kinetics and development. J. Cell Sci. 85: 197-215.

SPROULL, F. and DAVID, C.N. (1979a). Stem cell growth and differentiation in Hydra attenuata. I. Regulation of the self-renewal probability in multiclone aggregates. J. Cell Sci. 38: 155-169.

SPROULL, F. and DAVID, C.N. (1979b). Stem cell growth and differentiation in Hydra attenuata. II. Regulation of nerve and nematocyte differentiation in multiclone aggregates. J. Cell Sci. 38: 171-179.

STEELE, R.E. (2012). The Hydra genome: insights, puzzles, and opportunities for developmental biologists. Int J Dev Biol 56: 535-542.

SUGIYAMA, T. and FUJISAWA, T. (1977). Genetic analysis of developmental mechanisms in hydra I. Sexual reproduction of Hydra magnipapillata and isolation o mutants. Dev. Growth Differ. 19: 187-200.

TAKAHASHI, T., KOIZUMI, O., ARIURA, Y., ROMANOVITCH, A., BOSCH, T.C. KOBAYAKAWA, Y., MOHRI, S., BODE, H.R., YUM, S., HATTA, M. et al., (2000). A novel neuropeptide, Hym-355, positively regulates neuron differentiation in Hydra. Development 127: 997-1005.

TAKAHASHI, T., MUNEOKA, Y., LOHMANN, J., LOPEZDE HARO, M.S., SOLLEDER, G., BOSCH, T.C., DAVID, C.N., BODE, H.R., KOIZUMI, O., SHIMIZU, H. et al., (1997). Systematic isolation of peptide signal molecules regulating development in hydra: LWamide and PW families. Proc. Natl. Acad. Sci. USA 94: 1241-1246.

TARDENT, P. (1985). The differentiation of germ cells in Cnidaria. In The Origins and Evolution of Sex, pp. 163-197. New York: Alan R. Liss.

TECHNAU, U. and HOLSTEIN, T.W. (1996). Phenotypic maturation of neurons and continuous precursor migration in the formation of the peduncle nerve net in Hydra. Dev. Biol. 177: 599-615.

TERAGAWA, C.K. and BODE, H.R. (1995). Migrating interstitial cells differentiate into neurons in hydra. Dev. Biol. 171: 286-293.

TILL, J.E. and MCCULLOCH, C.E. (1961). A direct measurement of the radiation sensitivity of normal mouse bone marrow cells. Radiation Res. 14: 213-222.

VENUGOPAL, G. and DAVID, C.N. (1981a). Nerve commitment in Hydra. I. Role of morphogenetic signals. Dev. Biol. 83: 353-360.

VENUGOPAL, G. and DAVID, C.N. (1981b). Nerve commitment in Hydra. II. Localization of commitment in S phase. Dev. Biol. 83: 361-365.

VENUGOPAL, G. and DAVID, C.N. (1981c). Spatial pattern of nerve differentiation in Hydra is due to a pattern of nerve commitment. Dev. Biol. 83: 366-369.

WATANABE, H., HOANG, V.T., MATTNER, R. and HOLSTEIN, T.W. (2009). Immortality and the base of multicellular life: lessons from cnidarian stem cells. Sem. 
Cell Dev. Biol. 20: 1114-1125

WEISSMANN, A. (1883). Die Entstehung der Sexualzellen bei Hydromedusen, Jena Gustav Fischer Verlag. 1-295.
WITTLIEB, J., KHALTURIN, K., LOHMANN, J.U., ANTON-ERXLEBEN, F. and BOSCH T.C. (2006). Transgenic Hydra allow in vivo tracking of individual stem cells during morphogenesis. Proc. Natl. Acad. Sci. USA 103: 6208-6211.

\section{Further Related Reading, published previously in the Int. J. Dev. Biol.}

A polymorphic, thrombospondin domain-containing lectin is an oocyte marker in Hydractinia: implications for germ cell specification and sex determination

Brahim Mali, R. Cathriona Millane, Günter Plickert, Marcus Frohme and Uri Frank Int. J. Dev. Biol. (2011) 55: 103-108

\section{Frontiers in fluorescence microscopy}

José Rino, José Braga, Ricardo Henriques and Maria Carmo-Fonseca

Int. J. Dev. Biol. (2009) 53: 1569-1579

Wnt signaling in hydroid development: ectopic heads and giant buds induced by GSK-3beta inhibitors

Werner Müller, Uri Frank, Regina Teo, Ofer Mokady, Christina Guette and Günter Plickert Int. J. Dev. Biol. (2007) 51: 211-220

The role of alpha-amidated neuropeptides in hydroid development--LWamides and metamorphosis in Hydractinia echinata

Günter Plickert, Eva Schetter, Nicole Verhey-Van-Wijk, Jörg Schlossherr, Marlis Steinbüchel and Martin Gajewski

Int. J. Dev. Biol. (2003) 47: 439-450

Cnidarians as a model system for understanding evolution and regeneration

Brigitte Galliot and Volker Schmid

Int. J. Dev. Biol. (2002) 46: 39-48

5 yr ISI Impact Factor $(2010)=2.961$

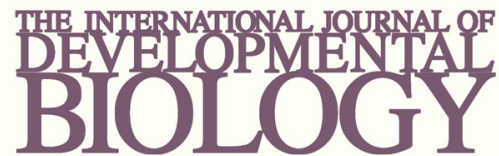

Volume 54 Nos. 6/7

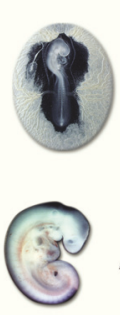

Special Issue

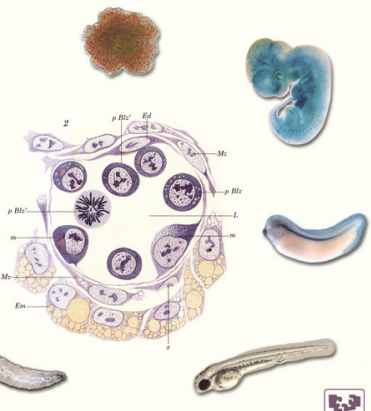

\$

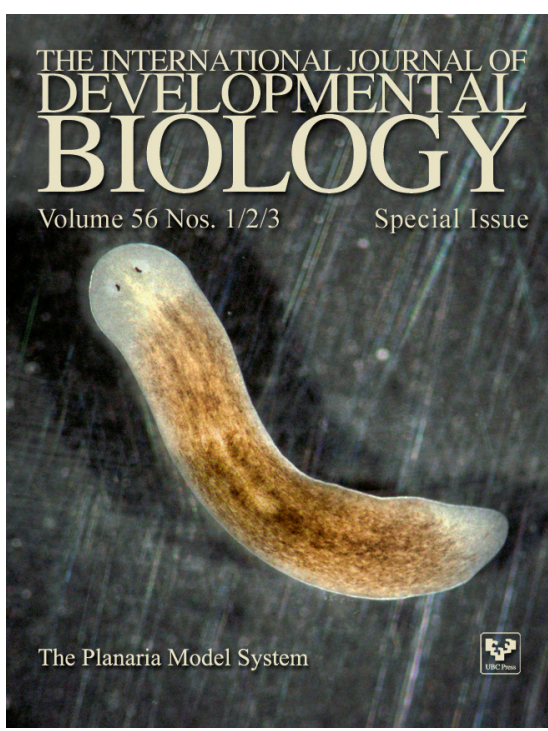

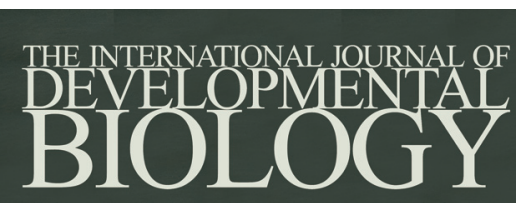

Volume 55 Nos. 4/5
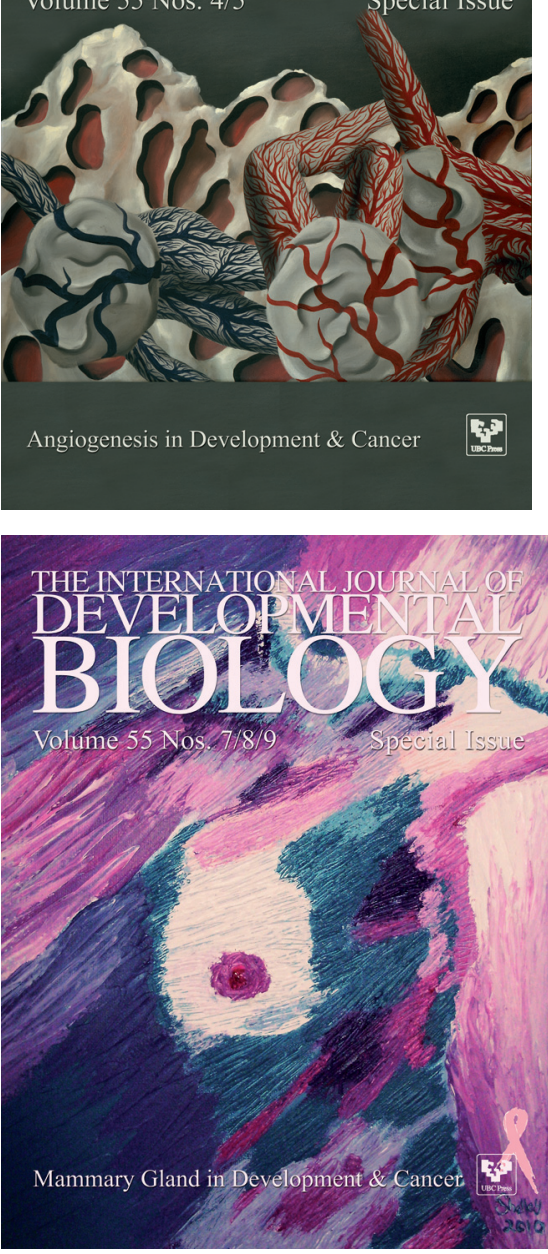